\title{
Presynaptic Facilitation of Glutamatergic Synapses to Dopaminergic Neurons of the Rat Substantia Nigra by Endogenous Stimulation of Vanilloid Receptors
}

\author{
Silvia Marinelli, ${ }^{1}$ Vincenzo Di Marzo, ${ }^{4}$ Nicola Berretta, ${ }^{1}$ Isabel Matias, ${ }^{4}$ Mauro Maccarrone, ${ }^{3}$ Giorgio Bernardi, ${ }^{1,2}$ and \\ Nicola B. Mercuri ${ }^{1,2}$ \\ ${ }^{1}$ Istituto di Ricovero e Cura a Carattere Scientifico Fondazione Santa Lucia and Departments of ${ }^{2}$ Neuroscience and ${ }^{3}$ Experimental Medicine and \\ Biochemical Sciences, University of Tor Vergata, 00179 Rome, Italy, and ${ }^{4}$ Endocannabinoid Research Group, Istituto di Chimica Biomolecolare, Consiglio \\ Nazionale delle Ricerche, 80078 Pozzuoli, Italy
}

Growing evidence regarding the function of vanilloid receptor-1 (VR1) in the brain suggests potential central roles of this receptor, previously described to occur primarily in peripheral sensory neurons. In the present study, we used electrophysiological and biochemical techniques to investigate the function and the endogenous stimulation of VR1 in dopaminergic neurons of the substantia nigra pars compacta (SNc). The VR1 agonist capsaicin increased the frequency of both TTX-sensitive and -insensitive spontaneous EPSCs (sEPSCs) without affecting their amplitude, suggesting a presynaptic site of action. In contrast, no effect was detected with regard to GABAergic transmission. No increase in sEPSC frequency was observed in the presence of cadmium chloride, while the voltage-dependent calcium channel antagonist $\omega$-conotoxin MVIIC did not prevent capsaicin action. The VR1 antagonists capsazepine and iodoresiniferatoxin (IRTX) blocked the effects of capsaicin. Importantly, IRTX per se reduced sEPSC frequency, suggesting a tonic activity of VR1. The endogenous VR1 agonist anandamide (AEA) produced an IRTX-sensitive increase in the frequency of sEPSCs on dopaminergic neurons that was more pronounced when protein kinase $\mathrm{A}$ had been activated. Furthermore, mass spectrometric analyses and binding experiments revealed high levels of endogenous AEA and specific binding of AEA to VR1 receptors in the SNc. These data suggest a tonic facilitation of glutamate release exerted by VR1 in the SNc through a stimulation of VR1 by endovanilloids, including anandamide. The increase in SEPSC frequency by VR1 onto midbrain dopaminergic neurons suggests the involvement of these receptors in motor and cognitive functions involving the dopaminergic system.

Key words: capsaicin; VR1; EPSCs; substantia nigra; anandamide; presynaptic mechanisms

\section{Introduction}

The recent demonstration of a widespread distribution of the mRNA for vanilloid receptor subtype-1 [VR1, also known as transient receptor potential vanilloid 1 (TRPV1)] and of VR1like immunoreactivity in the CNS (Sasamura et al., 1998; Mezey et al., 2000; Schumacher et al., 2000; Szabo et al., 2002) strongly suggests that these receptors are involved not only in peripheral functions such as perception of inflammatory and thermal pain (Caterina et al., 1997; Julius and Basbaum, 2001) but also in central responses. It is known that the "hot" chili pepper constituent capsaicin (Caterina et al., 1997; Tominaga et al., 1998; Kress and Zeilhofer, 1999; Smart et al., 2000) and the irritant extract from the Euphorbia resinifera, resiniferatoxin (RTX) activate these receptors (Acs et al., 1994). In addition protons, heat, and endogenous fatty acid derivatives such as anandamide (AEA) (Zygmunt et al., 1999; Smart et al., 2000; Di Marzo et al., 2001b),

\footnotetext{
Received Sept. 10, 2002; revised Jan. 13, 2003; accepted Jan. 13, 2003.

We thank Dr. Marco Capogna for helpful comments on this manuscript, Drs. Monica Bari and Natalia Battista for their skillful assistance in the binding experiments, Dr. Luciano De Petrocellis for valuable assistance in the RT-PCR experiments, and the VolkswagenStiftung for partial support (V.D.M.).

Correspondence should be addressed to Dr. Silvia Marinelli, Fondazione Santa Lucia Istituto di Ricovero e Cura a Carattere Scientifico, Experimental Neurology Laboratory, Via Ardeatina 306, 00179 Rome, Italy. E-mail: s.marinelli@hsantalucia.it.

Copyright $\odot 2003$ Society for Neuroscience $\quad 0270-6474 / 03 / 233136-09 \$ 15.00 / 0$
}

12-hydroperoxyeicosatetraenoic acid, and leukotriene $\mathrm{B}_{4}$ (Shin et al., 2002) and, more potently, $N$-arachidonoyl-dopamine (NADA) (Huang et al., 2002) can act as endogenous VR1 agonists.

With regard to the role of VR1 in the CNS, little is known of its function in the brain. Recent evidence suggests distinct actions in the hypothalamus, locus ceruleus, and hippocampus. In particular, capsaicin has been reported to increase the firing rate of hypothalamic preoptic neurons recorded in vivo (Hori et al., 1988) and the release of glutamate from hypothalamic slices (Sasamura et al., 1998). In the locus ceruleus, capsaicin activated firing (Hajos et al., 1987) and increased the frequency of excitatory postsynaptic currents (Marinelli et al., 2002a). However, capsaicin, anandamide, and NADA potentiate the GABA-dependent paired-pulse depression in the CA1 region of the hippocampus (Al-Hayani et al., 2001; Huang et al., 2002).

The basal ganglia is endowed with VR1-immunopositive cells, with the substantia nigra being an area with a strong signal (Mezey et al., 2000). Behavioral experiments have reported that an intranigral injection of capsaicin enhanced motor behavior (Dawbarn et al., 1981; Hajos et al., 1988), suggesting a functional role of these receptors in this area, but no direct investigations have been performed so far to elucidate VR1 function in the ventral midbrain.

We now present direct evidence of VR1 function in the sub- 
stantia nigra and demonstrate an excitatory role of these receptors, exerted through an increase in synaptic glutamate release onto the dopaminergic neurons. Moreover, we provide evidence for an endogenous activation of VR1 that tonically stimulates glutamate release in the dopaminergic system. Part of this work has been published previously in abstract form (Marinelli et al., 2002b).

\section{Materials and Methods}

Slice preparation. Wistar rats (12-24 d of age) were anesthetized with halothane and killed by decapitation. All experiments followed international guidelines on the ethical use of animals from the European Communities Council (EEC) Directive of November 24, 1986 (86/609/EEC). The brain was rapidly removed from the skull, and horizontal midbrain slices (300 $\mu \mathrm{m}$ ) were cut in cold artificial CSF (ACSF) using a vibratome and left to recover at $33^{\circ} \mathrm{C}$ for at least $1 \mathrm{hr}$. Slices were placed in a recording chamber and submerged in continuously flowing $\left(2.5 \mathrm{ml} / \mathrm{min}, 33-33.5^{\circ} \mathrm{C}\right)$ ACSF. ACSF composition was as follows (in mM): $126 \mathrm{NaCl}, 2.5 \mathrm{KCl}, 1.2 \mathrm{MgCl}_{2}, 2.4$ $\mathrm{CaCl}_{2}, 1.2 \mathrm{NaH}_{2} \mathrm{PO}_{4}, 19 \mathrm{NaHCO}_{3}$, and 10 glucose. In experiments using cadmium, $\mathrm{NaH}_{2} \mathrm{PO}_{4}$ and $\mathrm{CaCl}_{2}$ were omitted from ACSF.

Neurons were visualized using infrared Nomarski optics on an upright microscope (BX50WI; Olympus Optical, Hataguya, Shibuya-Ku, Japan). Patch-clamp recordings were obtained using glass electrodes (3-4 M $\Omega$ ) filled with (in mM): $150 \mathrm{~K}$-methylsulfate, $2 \mathrm{MgCl}_{2}, 0.1 \mathrm{EGTA}, 10 \mathrm{HEPES}$, $2 \mathrm{MgATP}$, and $0.3 \mathrm{Na}_{3} \mathrm{GTP}$, pH 7.4, with $\mathrm{KOH}$.

Whole-cell voltage-clamp recordings $(-60 \mathrm{mV}$ holding potential) were obtained using an Axopatch 1D (Axon Instruments, Foster City, CA). Spontaneous EPSCs (sEPSCs) and spontaneous IPSCs (sIPSCs) were filtered at $1 \mathrm{kHz}$, digitized at $10 \mathrm{kHz}$, and recorded on computer using pClamp8 software (Axon Instruments). Series resistances (8-15 $\mathrm{M} \Omega$ ) were not compensated, to maintain the highest possible signal-tonoise ratio; neurons in which series resistance varied by $>10 \%$ after drug application were rejected.

Evoked EPSCs were obtained in the presence of picrotoxin $(100 \mu \mathrm{M})$, after stimulation $(400 \mu \mathrm{sec}, 0.03 \mathrm{~Hz}$ ) with a bipolar $\mathrm{Ni} / \mathrm{Cr}$ electrode placed 50-100 $\mu \mathrm{m}$ rostral to the recording electrode. The stimulus intensity was set to obtain a half-maximal response.

Miniature events were detected in the presence of TTX (1.0 $\mu \mathrm{M})$. Glutamatergic and GABAergic synaptic events were isolated by recording in the presence of the $\mathrm{GABA}_{\mathrm{A}}$ receptor antagonist picrotoxin $(100 \mu \mathrm{M})$ or the ionotropic glutamate receptor antagonists CNQX $(10 \mu \mathrm{M})$ and AP-5 $(50 \mu \mathrm{M})$, respectively.

Spontaneous events were detected and analyzed with Mini Analysis software (Synaptosoft Inc, Leonia, NJ), using amplitude and area thresholds set as a multiple $(4-5 \times)$ of the SD of the noise. Each event was also visually inspected to prevent noise disturbance of the analysis.

The cumulative amplitude and interevent plots obtained for each cell in controls and after drug application were compared using the Kolmogorov-Smirnov (KS) test. The numerical data are given as mean \pm SEM and compared using the Student's $t$ test or the $\chi^{2}$ test. Each slice received only a single exposure to capsaicin or to other VR1 agonists.

Liquid chromatography-mass spectrometry analysis of rat midbrain slices for the presence of anandamide. The extraction and purification of anandamide from slices of the rat substantia nigra (10-15 mg wet tissue weight) were performed as described previously (Bisogno et al., 1997). First, tissues were homogenized and extracted with $50 \mathrm{~mm}$ chloroformmethanol-Tris-HCl, pH $7.5(2: 1: 1, \mathrm{v} / \mathrm{v})$, containing 5 pmol of $\left[{ }^{2} \mathrm{H}\right]_{8}$ anandamide as the deuterated internal standard. The lipid extract was purified and analyzed by liquid chromatography-atmospheric pressure chemical ionization-mass spectrometry (LC-APCI-MS) by using a Shimadzu HPLC apparatus (LC-10ADVP) coupled to a Shimadzu LCMS-2010 quadrupole MS via a Shimadzu APCI interface. MS analyses were performed in the selected ion monitoring mode as described previously (Di Marzo et al., 2001a), using conditions described by Di Marzo et al. (2000b). Anandamide was quantified by isotope dilution, and measured in picomoles normalized per gram of wet tissue weight.

Reverse-transcriptase PCR of rat midbrain slices RNA. Total RNA from slices of the rat substantia nigra was extracted using Trizol reagent (In- vitrogen, San Diego, CA). After extraction, RNA was precipitated using ice-cold isopropanol and resuspended in diethyl pyrocarbonate (Sigma, St. Louis, MO)-treated water; its integrity was verified after separation by electrophoresis into a $1 \%$ agarose gel containing ethidium bromide. RNA was further treated with RNase-free DNase I (DNA-free kit; Ambion, Austin, TX) to digest contaminating genomic DNA and to subsequently remove the DNase and divalent cations.

The expression of mRNAs for glyceraldehyde-3-phosphate dehydrogenase (GAPDH) and VR1 receptors was examined by reverse transcription (RT)-PCR. Total RNA was reverse-transcribed using oligo(dT) primers. DNA amplifications were performed in PCR buffer (Q-Biogen) containing $2 \mu \mathrm{l}$ of cDNA, $500 \mu \mathrm{M}$ deoxyNTP, 2 mM $\mathrm{MgCl}_{2}, 0.8 \mu \mathrm{M}$ of each primer, and $0.5 \mathrm{U}$ of Taq polymerase (Q-Biogen). The thermal reaction profile consisted of a denaturation step at $94^{\circ} \mathrm{C}$ for $1 \mathrm{~min}$, annealing at $60^{\circ} \mathrm{C}$ for $1 \mathrm{~min}$, and an extension step at $72^{\circ} \mathrm{C}$ for $1 \mathrm{~min}$. A final extension step of 10 min was performed at $72^{\circ} \mathrm{C}$. The PCR cycles were 35 for VR 1 and GAPDH and were observed to be optimal and in the linear portion of the amplification curve (data not shown). Reaction was performed in a PE Gene Amp PCR System 2400 (PerkinElmer Life Sciences, Emeryville, CA). After reaction, the PCR products were electrophoresed on a $2 \%$ agarose gel containing ethidium bromide for UV visualization. The specific oligonucleotides were synthesized on the basis of cloned human cDNA sequences of rat GAPDH and VR1. For GAPDH, the primer sequences were CCCTTCATTGACCTCAACTACATGGT (sense) and GAGGGGCCATCCACAGTCTTCTG (antisense). The VR1 sense and antisense primers were TCTATGATCGCAGGAGCATCTTCG and TCTGTGTAGCTGGCATTGACAAAC, respectively. The expected sizes of the amplicons were $470 \mathrm{bp}$ for GAPDH and $256 \mathrm{bp}$ for VR1.

Binding of $\left[{ }^{3} H\right]$ anandamide to rat midbrain slices. The binding of 200 $\mathrm{nm}\left[{ }^{3} \mathrm{H}\right]$ AEA to substantia nigra membrane fractions $(50 \mu \mathrm{g}$ protein/ test) was analyzed by rapid filtration assays as reported previously (Maccarrone et al., 2000). Nonspecific binding was determined in the presence of $1 \mu \mathrm{M}$ "cold" AEA (Maccarrone et al., 2000). Displacement of $\left[{ }^{3} \mathrm{H}\right] \mathrm{AEA}$ by the cannabinoid receptor type $1(\mathrm{CB} 1)$ or type $2(\mathrm{CB} 2)$ antagonists $\mathrm{N}$-piperidino-5-(4-chlorophenyl)-1-(2,4-dichlorophenyl)-4-methyl-3pyrazole carboxamide (SR141716) or $N$-[1(S)-endo-1,3,3-trimethyl bicyclo [2.2.1] heptan-2-yl]-5-(4-chloro-3-methylphenyl)-1-(4-methylbenzyl)-pyrazole-3-carboxamide (SR144528), respectively (Pertwee, 1997), or by the VR1 antagonist capsazepine (Zygmunt et al., 1999) was assessed by using each antagonist at a $1 \mu \mathrm{M}$ final concentration (Maccarrone et al., 2000).

Drug application. For the electrophysiological experiments, drugs were bath applied at the following final concentrations: picrotoxin $(100 \mu \mathrm{M})$, CNQX $(10 \mu \mathrm{M}), \operatorname{AP}-5(50 \mu \mathrm{M}), \operatorname{TTX}(1 \mu \mathrm{M})$ capsaicin $(1,3$, and $10 \mu \mathrm{M})$, AEA (10 and $30 \mu \mathrm{M})$, AM281 (500 nM), resiniferatoxin (300 nM), iodoresiniferatoxin (IRTX, $300 \mathrm{nM})$, capsazepine $(10 \mu \mathrm{M})$, forskolin $(10 \mu \mathrm{M})$, 4-AP $(10 \mu \mathrm{M})$, and $\omega$-conotoxin MVIIC $(1 \mu \mathrm{M})$. All drugs were obtained from Tocris Cookson (Bristol, UK), with the exception of TTX, which was obtained from Alomone Labs (Jerusalem, Israel), and 4-AP, which was supplied by Sigma. $\left[{ }^{3} \mathrm{H}\right]$ AEA $(223 \mathrm{Ci} / \mathrm{mmol})$ was purchased from NEN Life Science Products, Inc. (Boston, MA). SR141716 and SR144528 were a kind gift from Sanofi-Synthelabo (Montpellier, France).

Arvanil ( $N$-vanillyl-arachidonoyl-amide, $3 \mu \mathrm{M}$ ) was dissolved in DMSO and was synthesized at the Endocannabinoid Research Group. Capsaicin, capsazepine, AM281, RTX, and IRTX were dissolved in ethanol. AEA was dissolved in ethanol or in water-soluble emulsion. The final concentration of DMSO and ethanol was $<0.05 \%$.

\section{Results \\ Electrophysiological characteristics of the dopaminergic neurons}

Whole cell patch-clamp recordings were obtained from neurons of the substantia nigra pars compacta $(\mathrm{SNc})$. Most of the recorded neurons were located rostrally with respect to the medial terminal nucleus of the accessory optic tract. Dopaminergic neurons were identified on the basis of their electrophysiological properties (i.e., by the presence of a prominent time-dependent 
$I_{\mathrm{h}}$ ) in response to hyperpolarizing voltage steps (Mercuri et al., 1996).

\section{Vanilloid receptor-mediated modulation of} glutamatergic neurotransmission In the presence of the $\mathrm{GABA}_{\mathrm{A}}$ receptor antagonist picrotoxin $(100 \mu \mathrm{M})$, dopaminergic neurons displayed a spontaneous excitatory synaptic activity characterized by a mean frequency of $1.96 \pm 1.02 \mathrm{~Hz}$ $(n=11)$ and a mean amplitude of $15.98 \pm$ $1.70 \mathrm{pA}(n=11)$. In all tested neurons, perfusion of the selective VR1 agonist capsaicin ( $1 \mu \mathrm{M}, 3-5 \mathrm{~min}$ ) caused a significant increase in sEPSC frequency (187 \pm $45 \% ; n=8 ; p<0.005$; Student's paired $t$ test) (Fig. 1D). In each of these cells, the cumulative interevent distributions were statistically different ( $p \leq 0.001$; KS test) before and during capsaicin. The cumulative amplitude distributions were not significantly affected in five neurons ( $p>$ 0.05 ; KS test), whereas in the remaining three neurons, a reduction in sEPSC amplitude was observed ( $p<0.05$; KS test).

The effect of capsaicin was dosedependent. At $3 \mu \mathrm{M}$, capsaicin increased sEPSC frequency by $223 \pm 87 \%(n=4$; $p<0.005$; Student's paired $t$ test), and at $10 \mu \mathrm{M}$, the increase in sEPSC frequency attained was $388 \pm 115 \%(n=11 ; p<$ 0.001; Student's paired $t$ test) (Fig. $1 D$ ). In each cell, the cumulative interevent distribution in $10 \mu \mathrm{M}$ capsaicin was statistically different from controls $(p<0.001 ; n=$ 11; KS test) (Fig. $1 A-C$ ). The cumulative amplitude distribution was not significantly affected in nine neurons $(p>0.05$; KS test), whereas in the remaining two neurons, a reduction in sEPSC amplitude was detected ( $p<0.05$; KS test). A partial recovery of sEPSC frequency occurred within 10-15 min of capsaicin (1 or $10 \mu \mathrm{M})$ removal, but no complete washout of the effect was observed, even after $>30 \mathrm{~min}$.

We also investigated the effect of capsaicin on synaptically evoked EPSCs, after intranigral stimulation with a bipolar electrode, in the presence of picrotoxin $(100 \mu \mathrm{M})$. In each neuron, application of capsaicin $(10 \mu \mathrm{M})$ resulted in a decrease in EPSC amplitude, from $122.88 \pm 20.38$ to $95.90 \pm$ $19.36 \mathrm{pA}(p<0.05 ; n=6$; Student's paired $t$ test) (Fig. $1 E)$.

In 12 of 20 cells, capsaicin $(10 \mu \mathrm{M})$ induced an inward current of $17.4 \pm 3.0 \mathrm{pA}$. However, no change in the holding current was ever detected when capsaicin was applied in the presence of the glutamate ionotropic receptor antagonists CNQX $(10 \mu \mathrm{M})$ and AP-5 $(50 \mu \mathrm{M} ; n=13)$.

\section{Vanilloid receptors do not affect}

\section{GABAergic neurotransmission}

We then investigated possible effects of VR1 on spontaneous GABAergic synaptic transmission. Spontaneous IPSCs were recorded in the presence of CNQX $(10 \mu \mathrm{M})$ and AP-5 $(50 \mu \mathrm{M})$. respectively.
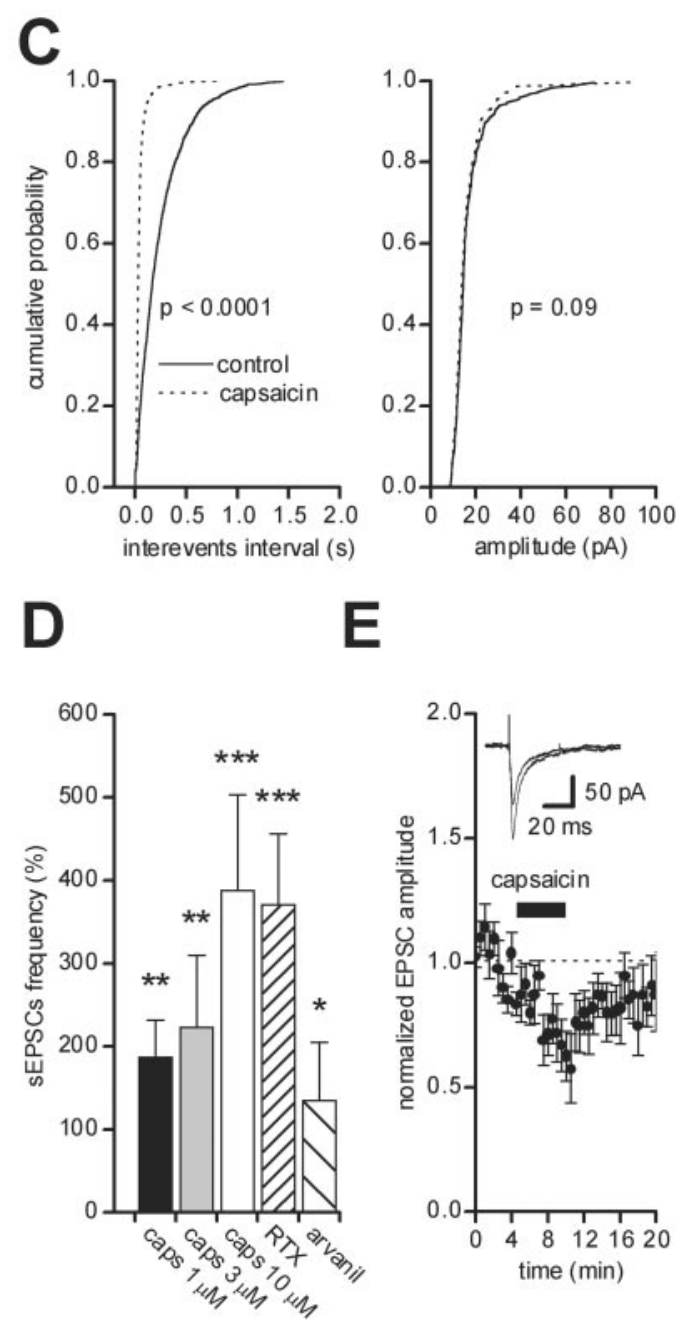

Figure 1. Effect of capsaicin on spontaneous and evoked EPSCs in dopaminergic neurons of the SNc. Recordings were performed in the presence of picrotoxin $(100 \mu \mathrm{M})$. A, Bath perfusion of capsaicin $(10 \mu \mathrm{M})$ for 2 min induced a slight inward current and an increase in sEPSC frequency. The top panel shows expanded trace records before (1) and during (2) capsaicin. B, Running average SEPSC frequency (top) and amplitude (bottom) of the recorded cell in $A$, showing the dramatic increase in SEPSC frequency without significant changes in sEPSC amplitude. C, Cumulative probability distributions of interevent intervals (left) and peak amplitude (right) from the neuron shown in $A$ in controls (solid line) and during capsaicin (dotted line). D, Summary $\mu \mathrm{M}$ arvanil) on the frequency of $S E P S(S . E$, Pooled data plot $(n=6)$ of normalized mean amplitude \pm SEM of evoked EPSC 政, showing the EPSC depression after perfusion with capsaicin $(10 \mu \mathrm{M})$. The inset shows two superimposed EPSCs from a single experiment, before and during perfusion with capsaicin. ${ }^{*} p<0.02,{ }^{* *} p<0.005$, and ${ }^{* * *} p<0.001$ versus control,

These synaptic currents were sensitive to the $\mathrm{GABA}_{\mathrm{A}}$ receptor antagonist picrotoxin (100 $\mu \mathrm{M}$, data not shown).

No significant changes in sIPSC frequency were detected after capsaicin $(10 \mu \mathrm{M}, 2-3 \mathrm{~min})$ perfusion (before drug, $2.59 \pm 0.71$ $\mathrm{Hz}, n=10$; after drug, $2.58 \pm 0.56 \mathrm{~Hz}, n=10 ; p>0.02$; Student's paired $t$ test), and no significant changes in sIPSC amplitude were observed either (before drug, $27.24 \pm 2.02 \mathrm{pA}, n=10$; after drug, $26.36 \pm 2.01 \mathrm{pA}, n=10 ; p>0.02$; Student's paired $t$ test). In each of these cells, no significant changes were detected in the cumulative distributions for both sIPSC frequency $(p>0.05 ; n=10$; KS test) and sEPSC amplitude ( $p>0.05 ; n=10$; KS test) (Fig. 2 ).

\section{Capsaicin effects on miniature EPSCs}

To investigate whether the VR1-mediated increase in sEPSC frequency was secondary to action potential generation on glutamatergic afferents, we repeated the same experiments on 
A

(1)
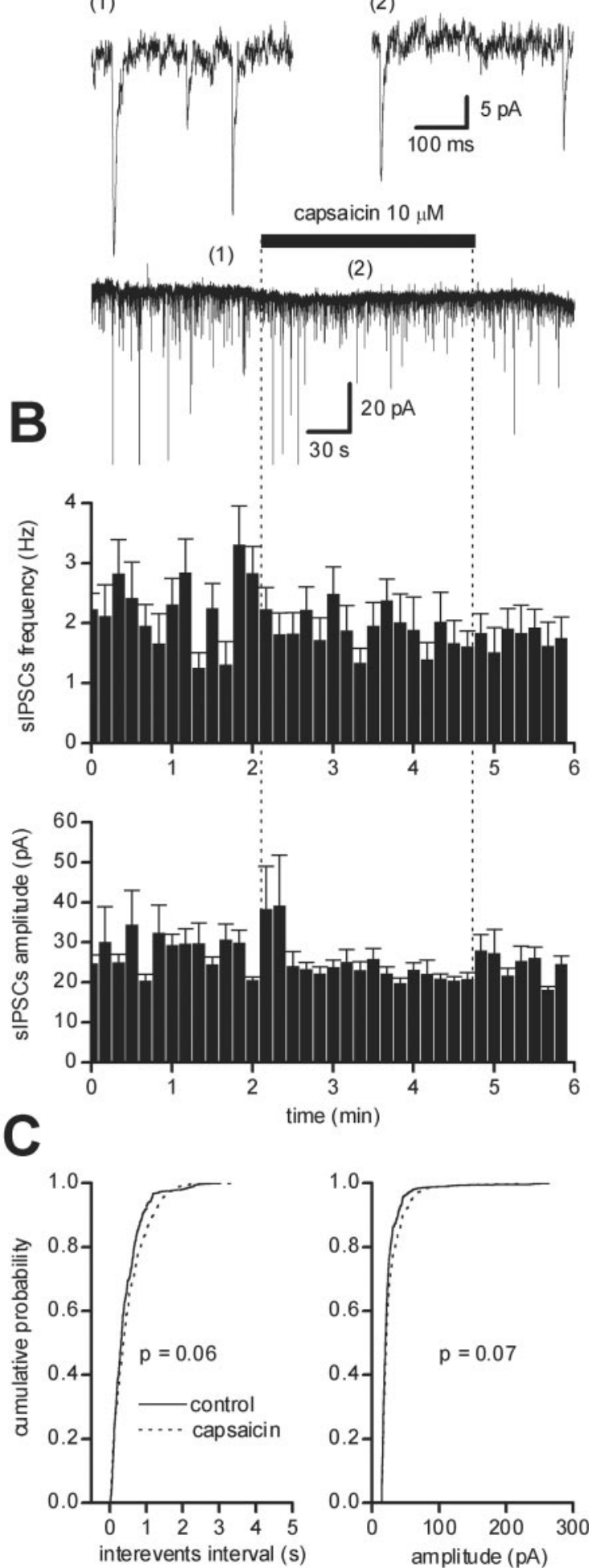

(2)

(2)

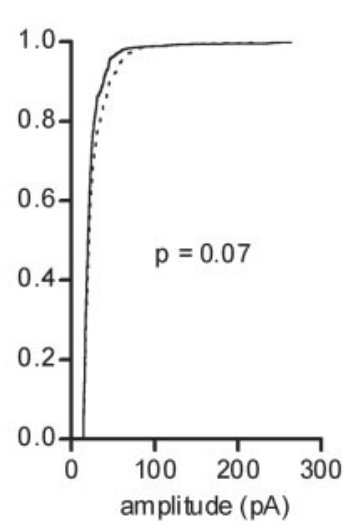

Figure 2. Effect of capsaicin on sIPSCs in dopaminergic neurons of the SNc. Recordings were performed in the presence of CNQX $(10 \mu \mathrm{M})$ and AP-5 $(50 \mu \mathrm{M})$. A, Bath perfusion of capsaicin (10 $\mu \mathrm{m})$ did not induce any significant effect on the holding current or on SIPSCS. The top panel shows expanded trace records before (1) and during (2) capsaicin. $B$, Running average histogram of sIPSC frequency (top) and amplitude (bottom) of the recorded cell in $A$, showing no significant modifications of sIPSC frequency and amplitude. C, Cumulative probability distributions of interevent intervals (left) and of the peak amplitude (right) of sIPSCs from the neuron shown in $A$ in controls (solid line) and during capsaicin (dotted line). miniature events in the presence of TTX $(1 \mu \mathrm{M})$. Miniature EPSCs (mEPSCs) had a mean frequency of $1.38 \pm 0.32 \mathrm{~Hz}$ and a mean amplitude of $13.74 \pm 0.80 \mathrm{pA}(n=8)$. In all tested neurons, capsaicin $(10 \mu \mathrm{M}, 2-3 \mathrm{~min})$ induced a significant increase in mEPSC frequency $(301 \pm 125 \% ; n=8 ; p \leq 0.02$; Student's paired $t$ test). In each of these cells, the cumulative interevent distributions were statistically different $(p<0.001$; KS test) before and during capsaicin, but the cumulative amplitude distribution was not significantly affected $(n=8 ; p>$ 0.05; KS test) (Fig. 3A-C).

\section{Calcium dependence of VR1-mediated excitatory effects}

To investigate whether the increase in glutamate synaptic release after VR1 activation was dependent on calcium influx, we removed calcium from the external medium and added $\mathrm{CdCl}_{2}(100$ $\mu \mathrm{M})$ in the presence of TTX $(1 \mu \mathrm{M})$. This procedure on its own reduced the frequency (from $1.71 \pm 0.47$ to $0.90 \pm 0.32 \mathrm{~Hz} ; n=$ $5 ; p<0.05$; Student's paired $t$ test) but not the amplitude (from $16.13 \pm 2.56$ to $15.87 \pm 2.42 \mathrm{pA} ; n=5 ; p=0.34$; Student's paired $t$ test) of mEPSCs (data not shown). Under these experimental conditions, capsaicin $(10 \mu \mathrm{M}, 2-3 \mathrm{~min}) \mathrm{did}$ not produce any increase in mEPSC frequency $(p>0.05 ; n=5$; KS test) or in mEPSC amplitude ( $p>0.05 ; n=5$; KS test) (Fig. $3 D)$.

VR1 is an ionotropic receptor whose ionophore is a nonselective cationic channel (Caterina et al., 1997). To separate a possible effect of cadmium on VR1 from that on voltage-dependent calcium channels (VDCCs), we performed experiments in the presence of the wide spectrum blocker of N-, P-, and Q-type calcium channels, $\omega$-conotoxin MVIIC. No changes were observed in sEPSC frequency or in sEPSC amplitude after perfusion with $\omega$-conotoxin MVIIC ( $1 \mu \mathrm{M}$, data not shown). As shown in Figure $3 E$, in all neurons tested in the presence of this VDCC antagonist, capsaicin $(10 \mu \mathrm{M})$ significantly increased the frequency of sEPSCs ( $p<0.001 ; n=5$; KS test) without affecting their amplitude ( $p>0.05 ; n=5$; KS test). However, the degree of the capsaicininduced increase in sEPSC frequency under control conditions was significantly higher than that in the presence of $\omega$-conotoxin MVIIC (388 \pm 115 vs $33 \pm 28 \%$, respectively; $p<0.001 ; \chi^{2}$ test $)$.

\section{Capsaicin effects are mimicked by other VR1 agonists and blocked by VR1 antagonists}

To confirm that the observed results with capsaicin were caused by VR1 activation, we used other known VR1 agonists. RTX (300 $\mathrm{nM}, 2-3 \mathrm{~min})$ and arvanil $(3 \mu \mathrm{M})$ both induced a significant increase in sEPSC frequency (RTX, $371 \pm 85 \%, n=4, p<0.001$, Student's paired $t$ test; arvanil, $135 \pm 70 \%, n=4, p<0.02$, Student's paired $t$ test) (Fig. $1 D$ ). No change in sEPSC amplitude was observed with either of the two VR1 agonists $(p>0.05$; Student's paired $t$ test; data not shown). Because arvanil is a structural "hybrid" between the endogenous cannabinoid CB1 receptor ligand anandamide and capsaicin (Melck et al., 1999), it was applied in the presence of the CB1 receptor antagonist AM281 (500 nM).

The increase in glutamatergic neurotransmission induced by capsaicin was blocked by specific VR1 antagonists. When slices were preincubated with the competitive VR1 antagonist capsazepine $(10 \mu \mathrm{M}, 60 \mathrm{~min})$, capsaicin $(10 \mu \mathrm{M})$ did not increase mEPSC frequency ( $92 \pm 16 \%$ of controls; $n=5$; data not shown). We also used the novel and potent VR1 antagonist IRTX (Wahl et al., 2001). Acute application of IRTX (300 nM) reduced on its own the frequency of sEPSCs from $2.25 \pm 1.40$ to $1.59 \pm 1.63 \mathrm{~Hz}(p<$ $0.05 ; n=7$; Student's paired $t$ test), without changing their amplitude (from $13.19 \pm 1.74$ to $13.39 \pm 2.15 \mathrm{pA} ; n=7 ; p>0.05$; 
Student's paired $t$ test). In each cell, IRTX (300 nM) produced a significant leftward shift of the interevent interval $(p<0.002$; $n=7$; KS test), but the cumulative amplitude distribution was not significantly affected ( $p>0.05 ; n=7$; KS test) (Fig. $4 A, B)$. In the continuous presence of IRTX, perfusion of capsaicin $(10 \mu \mathrm{M})$ in each cell did not increase sEPSC frequency (from $2.159 \pm 0.60$ to $1.847 \pm$ $0.71 \mathrm{~Hz} ; p>0.05$; KS test; $n=5$ ) and did not modify sEPSC amplitude (from $11.77 \pm 1.11$ to $11.11 \pm 1.02 \mathrm{pA} ; p>0.05$; $n=5$; KS test) (Fig. 4C).

Endogenous compounds modulate the spontaneous synaptic transmission

The observed acute effects of IRTX indicate that VR1s are tonically active and suggest the presence of an endogenous agonist of these receptors in the ventral midbrain. VR1s have been shown to be activated by the endocannabinoid AEA (Zygmunt et al., 1999; Smart et al., 2000); therefore, we investigated the effects of AEA on sEPSCs of dopaminergic neurons. Perfusion with AEA $(10 \mu \mathrm{M})$ in the presence of the CB1 antagonist AM281 $(500 \mathrm{~nm})$ did not change the frequency and the amplitude of the sEPSCs $(p>$ 0.05; KS test; $n=5$ ) (Fig. $5 A$ ); however, a higher concentration of AEA $(30 \mu \mathrm{M})$ increased sEPSC frequency in three of six neurons ( $p<0.005$; KS test) without changing sEPSC amplitude ( $p>0.05$; KS test). One of the neurons in which $30 \mu \mathrm{M}$ AEA was effective is shown in Figure $5 B$. The need for high concentrations of AEA may be the result of a lower potency and efficacy for VR1 of AEA compared with capsaicin (Zygmunt et al., 1999; Smart et al., 2000). Therefore, we investigated the effects of AEA $(10 \mu \mathrm{M})$ in the presence of the adenylate cyclase activator forskolin (FSK), which has been shown to increase the potency of AEA at VR1 (De Petrocellis et al., 2001). FSK (10 $\mu \mathrm{M})$ increased on its own the frequency of sEPSCs, from $2.83 \pm 0.97$ to $4.65 \pm 1.41(n=4 ; p<0.05$; Student's paired $t$ test), without changing their amplitude $(13.11 \pm 0.31$ and $13.82 \pm 0.92 \mathrm{pA}$ in control and forskolintreated cells, respectively; $n=4 ; p>0.4$; Student's paired $t$ test). Within $8 \mathrm{~min}$, the FSK-induced increase in sEPSC frequency reached a steady-state level. Application of AEA $(10 \mu \mathrm{M})$ in the continuous presence of AM281 (500 nM) and FSK (10 $\mu \mathrm{M})$ elicited a significant increase in sEPSC frequency, from $3.89 \pm 1.33$ to $5.27 \pm 1.38 \mathrm{~Hz}(n=5 ; p<0.05$; Student's paired $t$ test $)$, without affecting sEPSC amplitude (from $13.16 \pm 0.17$ to $12.79 \pm 0.34 \mathrm{pA} ; n=5 ; p>0.05$; Student's paired $t$ test). In each tested neuron, the effects of AEA in the presence of FSK were statistically significant with regard to cumulative sEPSC frequency distribution ( $p<0.001 ; n=5$; KS test) but not with regard to cumulative sEPSC amplitude distribution $(p>0.05$; $n=5$; KS test) (Fig. 5C). Similar results were obtained when FSK (dotted line).

\section{C}
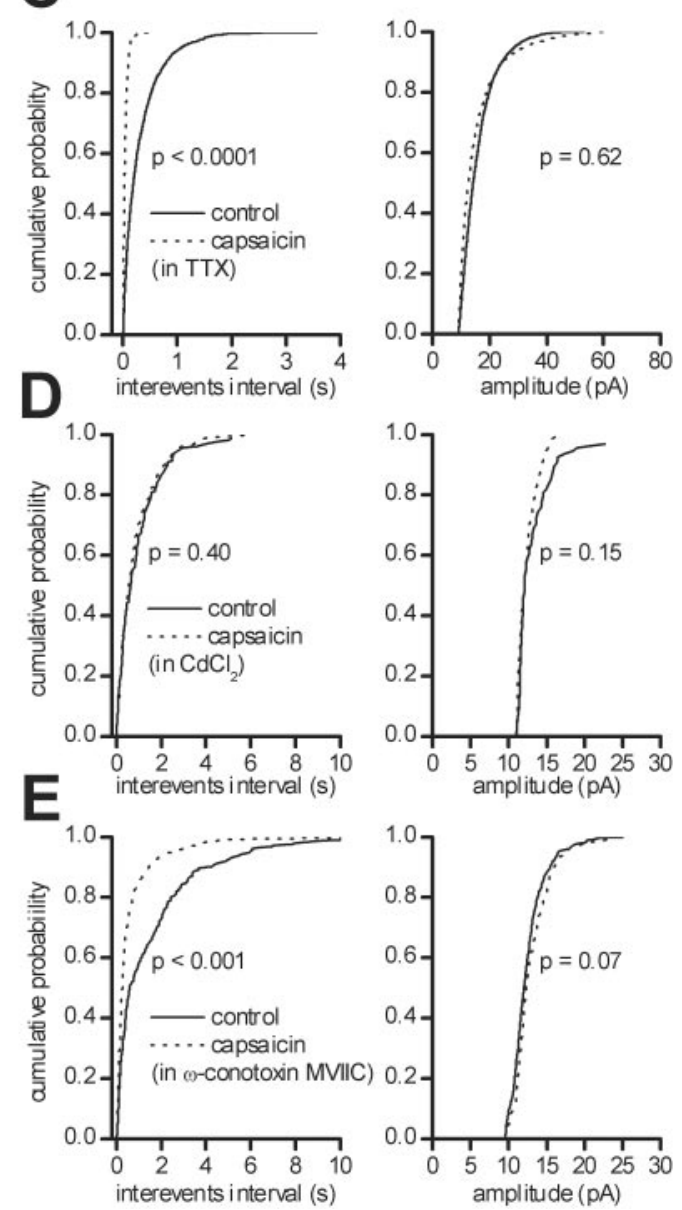

Figure 3. Action potential and calcium dependence of the excitatory effects of capsaicin. Recordings were performed in the presence of picrotoxin $(100 \mu \mathrm{m})$ and TTX $(1 \mu \mathrm{M})$. A, Bath perfusion of capsaicin (10 $\mu \mathrm{M})$ for 2 min induced an increase in mEPSC frequency. The top panel shows expanded trace records before (1) and during (2) capsaicin. $B$, Running average histogram of the amplitude (right) of mEPSCs from the neuron shown in $A$ in controls (solid line) and during capsaicin (dotted line). $D$, Cumulative probability distributions of interevent intervals (left) and of the peak amplitude (right) of mEPSCs from a single neuron recorded in the presence of TTX $(1 \mu \mathrm{m})$ and $\mathrm{CdCl}_{2}(100 \mu \mathrm{m})$ in controls (solid line) and in the presence of $10 \mu \mathrm{m}$ capsaicin (dotted line). $E_{,}$ Cumulative probability distributions of interevent intervals (left) and of the peak amplitude (right) of mEPSCs from a single neuron recorded in the presence of TTX $(1 \mu \mathrm{M})$ and $\omega$-conotoxin MVIIC (1 $\mu \mathrm{m})$ in controls (solid line) and in the presence of $10 \mu \mathrm{M}$ capsaicin

and AM281 were applied in the presence of TTX $(1 \mu \mathrm{M})$. Under these conditions, AEA produced a significant leftward shift of the interevent interval ( $p<0.02$; KS test; $n=6$ ), but the cumulative amplitude distribution was not significantly affected $(p>0.05$; $n=6$; KS test).

To investigate how specific the effects of FSK were in facilitating AEA action, we repeated the same experiments in the presence of 4-AP $(10 \mu \mathrm{M})$, which, similarly to FSK, also increases the presynaptic release probability. Under these conditions, AEA did not produce any significant increase in sEPSC frequency $(p>$ $0.05 ; n=5$; KS test).

In the presence of the VR1 antagonist IRTX (300 nM), the increase in sEPSC frequency by $10 \mu \mathrm{M}$ AEA in FSK and AM281 was prevented $(2.39 \pm 0.38$ and $2.26 \pm 0.38 \mathrm{~Hz} ; n=4 ; p>$ 0.05; Student's paired $t$ test). In each of these neurons, no significant shift in the interevent interval distribution was induced by AEA ( $p>0.05 ; n=4$; KS test), and no shift was 
A control IRTX capsaicin (in IRTX)
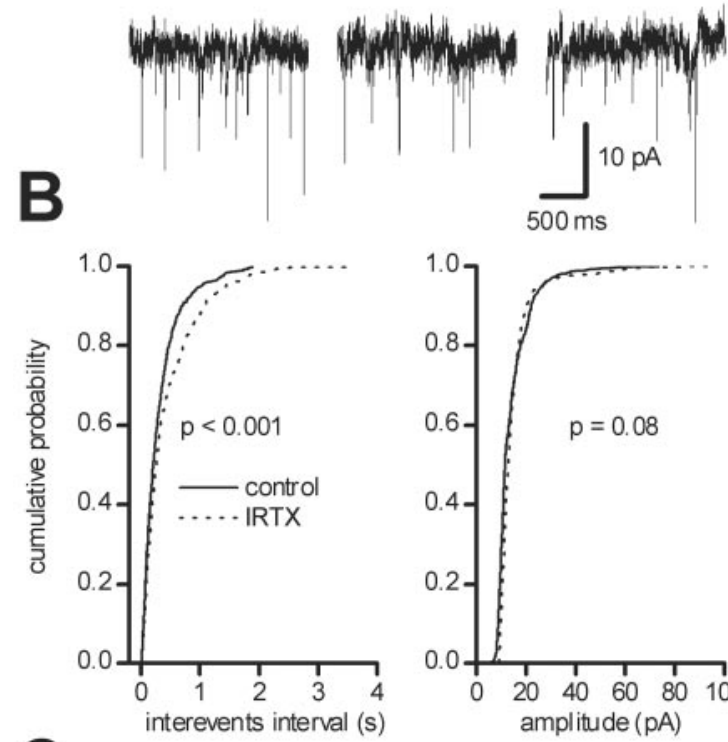

$500 \mathrm{~ms}$
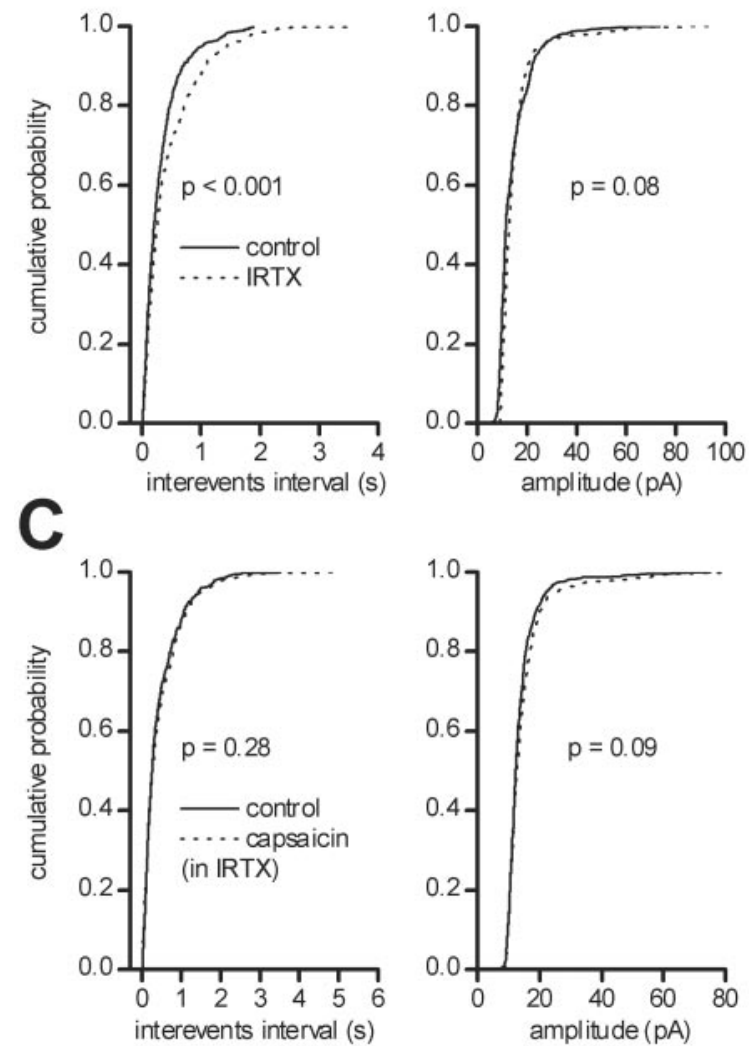

Figure 4. Tonic control of glutamatergic neurotransmission by VR1s. Recordings were performed in the presence of picrotoxin $(100 \mu \mathrm{M})$. A, Trace records from a single dopaminergic neuron under control conditions (left) and in the presence of the VR1 antagonist IRTX ( $300 \mathrm{~nm}$, middle). Under these conditions, sEPSC frequency was reduced. In the presence of IRTX, capsaicin $(10 \mu \mathrm{M})$ was no longer able to produce a facilitation of glutamatergic neurotransmission (right). $B$, Cumulative probability distributions of interevent intervals (left) and of peak amplitude (right) from the neuron shown in $A$ in controls (solid line) and in the presence of $300 \mathrm{~nm}$ IRTX (dotted line). C, Cumulative probability distributions of interevent intervals (left) and of peak amplitude (right) of the neuron shown in $A$ in $300 \mathrm{~nm}$ IRTX (solid line) and in IRTX plus 10 $\mu \mathrm{m}$ capsaicin (dotted line).

seen in the amplitude distribution ( $p>0.05 ; n=4$; KS test) (Fig. 5D).

\section{Anandamide and VR1 receptors are present in rat midbrain slices}

To provide more direct evidence of VR1 tonic activation by the endogenous agonist anandamide, we investigated the presence of this compound as well as the expression of VR1 mRNA in rat midbrain slices identical to those used for the electrophysiological studies. By using an ultra-sensitive LC-MS technique, we found levels of anandamide $(382.5 \pm 145.2$ pmol per gram of wet tissue weight; $n=4)$ that are relatively high compared with other rat tissues (Bisogno et al., 1999) but similar to those described previously for the rat substantia nigra (Di Marzo et al., 2000a). By using RT-PCR amplification of rat midbrain slice RNA, we also found a band of the expected size for the rat VR1 cDNA transcript, which was absent when amplifying nonretrotranscripted RNA (Fig. 6A). Finally, substantia nigra membranes were able to bind $\left[{ }^{3} \mathrm{H}\right] \mathrm{AEA}$, and $1 \mu \mathrm{M}$ cold AEA fully prevented this binding (Fig. 6B). SR141716, but not SR144528 (each used at $1 \mu \mathrm{M}$ ), displaced $\sim 65 \%$ of bound $\left[{ }^{3} \mathrm{H}\right] \mathrm{AEA}(n=4 ; p<0.01$; Student's paired $t$ test), whereas $1 \mu \mathrm{M}$ capsazepine displaced $\sim 35 \%$ of it ( $n=4 ; p<0.05$; Student's paired $t$ test).

\section{Discussion}

The results of this study indicate that the stimulation of VR1 in the ventral midbrain selectively stimulates the glutamatergic inputs onto dopaminergic neurons, without affecting the GABAergic neurotransmission. Our results are in agreement with previous studies in the hypothalamus, the locus ceruleus, the substantia gelatinosa, and the dorsal horn of the spinal cord, showing that VR1 activation enhances glutamatergic release (Sasamura et al., 1998; Yang et al., 1998; Marinelli et al., 2002a; Nakatsuka et al., 2002) with no effect on GABA release (Yang et al., 1998). The effects of capsaicin on glutamatergic transmission were indeed attributable to stimulation of VR1, because they were blocked by two VR1 antagonists, capsazepine and the ultrapotent and selective IRTX. Moreover, the effect of capsaicin was dose-dependent, and three other VR1 agonists, RTX, arvanil, and anandamide, also enhanced sEPSC frequency.

The increase in sEPSC and mEPSC frequency by VR1 stimulation, with no modification, or occasionally even with a reduction in amplitude, strongly suggests that these effects are attributable to an increase in presynaptic release probability. A similar increase in presynaptic glutamate release by VR1s has been demonstrated in the locus ceruleus, the substantia gelatinosa, and the dorsal horn of the spinal cord (Urban and Dray, 1992; Yang et al., 1998; Marinelli et al., 2002a; Nakatsuka et al., 2002).

The increase in glutamate release after VR1 stimulation was dependent on calcium influx from the external medium, because no significant change in sEPSC frequency was detected in experiments with cadmium and no added calcium. However, results obtained with $\omega$-conotoxin MVIIC suggested that capsaicin may increase the probability of glutamate release through calcium influx via the ionophore of VR1. However, the effects of capsaicin in the presence of $\omega$-conotoxin MVIIC were significantly smaller than in controls. This indicates that VR1 stimulation may exert excitatory effects through calcium influx from both its own ionophore and the VDCCs, with a mechanism similar to that suggested for the locus ceruleus (Marinelli et al., 2002a).

The VR1-mediated reduction of evoked EPSCs reported in this study is similar to that observed in dorsal root neurons (Yang et al., 1998). A conceivable hypothesis for this effect is that a sustained depolarization of afferent glutamatergic terminals may facilitate spontaneous glutamate release while reducing action potential-evoked responses by a depolarization block (Katz and Miledi, 1969). In a subset of recorded neurons, sEPSC amplitude was also reduced by capsaicin. This result may again be caused by an excessive depolarization of the presynaptic terminal. Alternatively, we cannot exclude the heterogeneity of the action of capsaicin, which may occasionally involve both presynaptic and postsynaptic modifications.

Microscopic analysis and anterograde tracer techniques have shown that the main glutamatergic inputs to the ventral midbrain originate from the frontal cortex, subthalamic nucleus, and pedunculopontine nucleus, while minor sources include the amygdaloid complex (Jackson and Crossman, 1983; Kita and Kitai, 
A

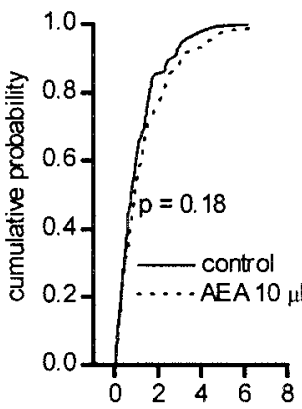

interevents interval (s)

B
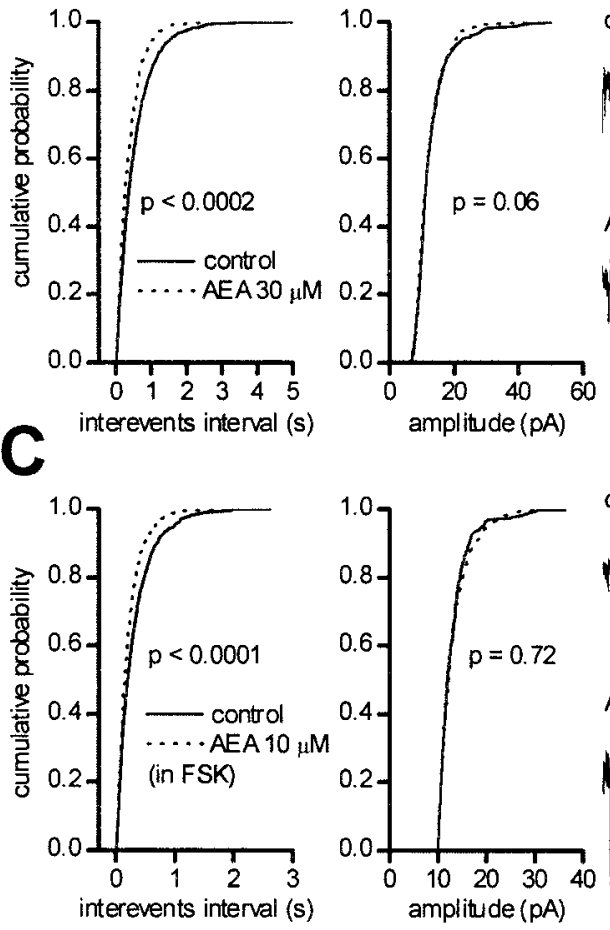

control (in FSK)

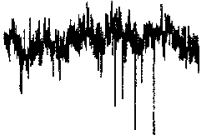

AEA $10 \mu \mathrm{M}$ (in FSK)

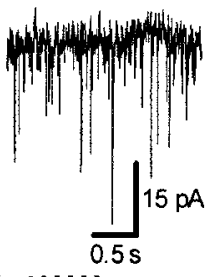

$\mathbf{D}$
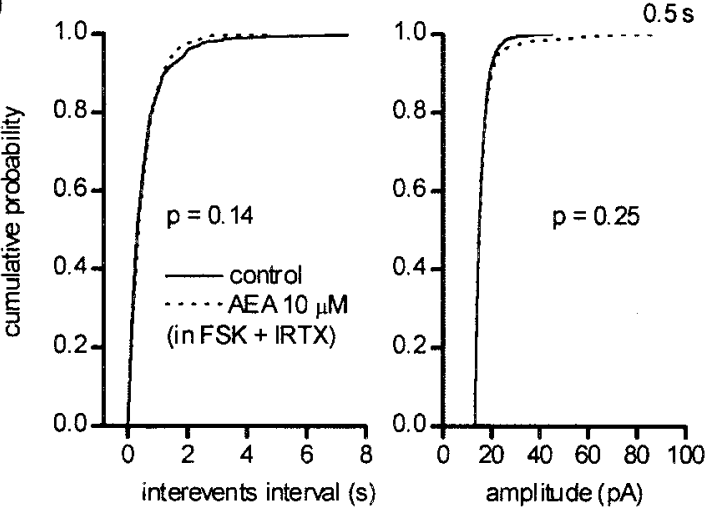

Figure 5. Facilitation of glutamatergic neurotransmission by the endocannabinoid AEA. Recordings were performed in the presence of picrotoxin $(100 \mu \mathrm{M})$. A, Cumulative probability distributions of interevent intervals (left) and of peak amplitude (right) from a single neuron in controls (solid line) and in the presence of $10 \mu \mathrm{m} A E A$ (dotted line). Trace records from the same neurons are shown on the right. $B$, Cumulative probability distributions of interevent intervals (left) and of peak amplitude (right) from a single neuron in controls (solid line) and in the presence of $30 \mu \mathrm{m}$ AEA (dotted line). Trace records from the same neurons are shown on the right. C, Cumulative probability distributions of interevent intervals (left) and of peak amplitude (right) from a single neuron in the continuous presence of FSK (10 $\mu \mathrm{m})$ before (solid line) and

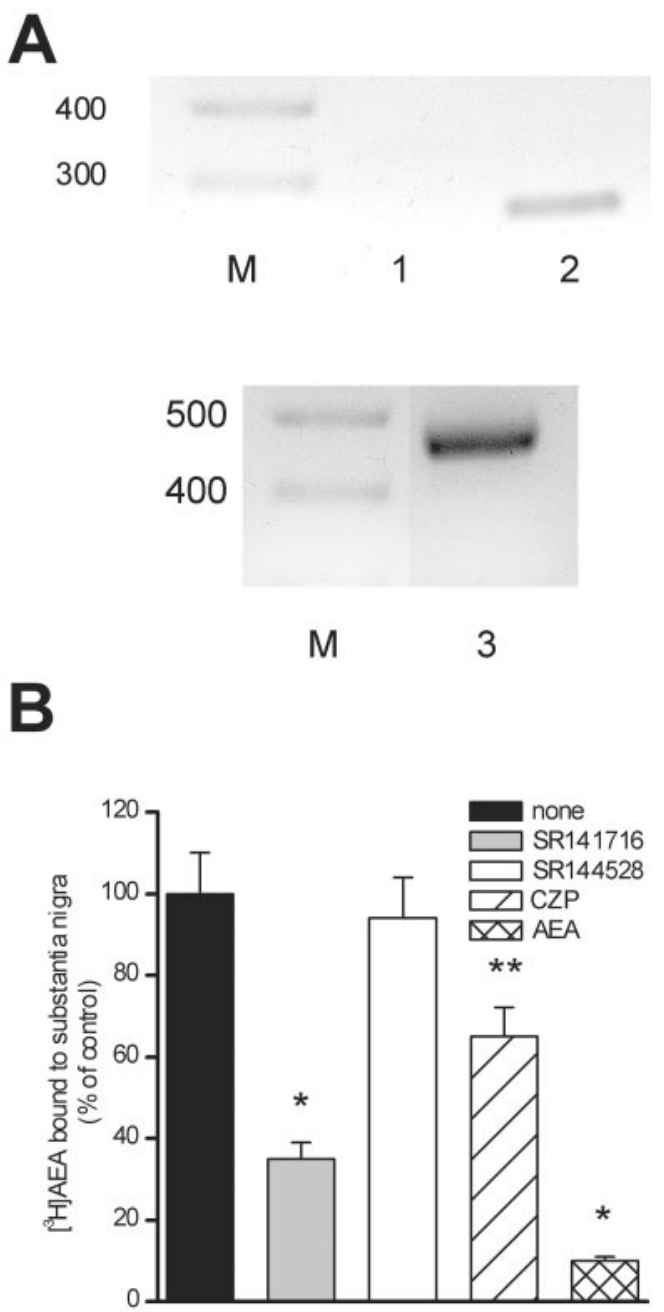

Figure 6. A, RT-PCR analysis of total RNA from rat midbrain slices to determine the presence of a transcript for rat VR1. Lane 2 shows the band of the expected size (256 bp) obtained from rat VR1 cDNA transcript. Lane 3 shows the GAPDH transcript ( 470 bp). A 100 bp ladder is also shown on the left side of each gel. M, Size markers; lane 1, nonretrotranscribed total RNA. B, Binding of $\left[{ }^{3} \mathrm{H}\right] \mathrm{AEA}$ to substantia nigra membranes. The binding of $200 \mathrm{~nm}\left[{ }^{3} \mathrm{H}\right] \mathrm{AEA}$ was measured in the absence or in the presence of the $C B 1$ or $C B 2$ receptor antagonists SR141716 or SR144528, of the VR1 antagonist capsazepine (CZP), or of cold AEA, each used at $1 \mu \mathrm{m}(100 \%=5300 \pm 500$ dpm). ${ }^{*} p<0.01$ and ${ }^{* *} p<0.05$ versus controls.

1987; Naito and Kita, 1994; McDonald, 1996). Considering the high density of VR1 in the frontal cortex and amygdala (Mezey et al., 2000), it is possible that the glutamatergic terminals expressing VR1 may arise from these regions.

Previous anatomical results have shown a double-labeling immunofluorescence with an overlap between VR1-positive and tyrosine hydroxylase-positive cells in the substantia nigra (Mezey et al., 2000), suggesting a somatic localization of VR1 onto the dopaminergic neurons. However, our electrophysiological data indicate that the main result of VR1 activation is a presynaptic change in release probability. In a subset of recorded neurons $(60 \%)$ we did observe a slow inward current with capsaicin (10 $\mu \mathrm{M})$ that could be caused by postsynaptic VR1s; however, no

during perfusion with $10 \mu \mathrm{m}$ AEA (dotted line). Trace records from the same neurons are shown on the right. $D$, Cumulative probability distributions of interevent intervals (left) and of peak amplitude (right) from a single neuron in the continuous presence of FSK (10 $\mu \mathrm{M})$ and of the VR1 antagonist IRTX ( $300 \mathrm{~nm}$ ) before (solid line) and during perfusion with $10 \mu \mathrm{M}$ AEA (dotted line). 
inward current was ever detected in the presence of CNQX and AP-5. This indicates that this postsynaptic current needed active glutamate receptors to be expressed, or, more likely, that it was secondary to the increased presynaptic glutamate release. In line with our observations, in dorsal horn neurons, the stimulation of C-fibers with capsaicin can also induce a long-lasting membrane depolarization blocked by glutamatergic antagonists (Urban and Dray, 1992). The apparent lack of direct postsynaptic effects caused by the activation of VR1s could be attributable to nonfunctional VR1 protein present on the soma of dopaminergic neurons. Alternatively, recent studies have identified two types of capsaicin-insensitive vanilloid receptor-like proteins (VRL-1, VRL-2), (Schumacher et al., 2000; Smith et al., 2002; Xu et al., 2002), both of which are expressed in the brain. It is possible that the use of nonselective antibodies by Mezey et al. (2000) may have led to labeling of a postsynaptic TRPV subtype different from VR1, whose physiological role in the substantia nigra has yet to be identified. In addition, we cannot exclude an involvement of the release of some retrograde messenger, after stimulation of the postsynaptic VR1s. This hypothesis is at this stage speculative. In preliminary experiments with cells loaded with BAPTA, VR1 stimulation still produced an increase in sEPSC frequency $(n=3$; data not shown), indicating that if a retrograde messenger is released, this process does not require an increase in postsynaptic calcium.

An important result of our study is that the VR1 antagonist IRTX not only prevented the effect of capsaicin but also reduced per se the sEPSC frequency. This finding suggests a tonic control of glutamate neurotransmission through activation of VR1s by endogenous factors. Growing evidence suggests that vanilloid receptors can be activated by the endocannabinoid AEA (for review, see Di Marzo et al., 2001b). First, AEA has a similar structure to synthetic vanilloid agonists (Di Marzo et al., 1998b; Szallasi and Di Marzo, 2000); second, AEA produces vasodilatatory effects resistant to cannabinoid antagonists (White and Hiley, 1998); and third, AEA exhibits partial and full agonism at rat and human VR1s, respectively (Zygmunt et al., 1999; Smart et al., 2000). Our data suggest that AEA may be one of the endogenous agonists of VR1s in the midbrain, because in the presence of the CB1 antagonist AM281, AEA induced an IRTX-sensitive increase in glutamate release probability. The effect of $10 \mu \mathrm{M}$ AEA was more pronounced and consistent when it was coapplied with FSK. Moreover, FSK was also able to facilitate the action of AEA in the presence of TTX, suggesting a specific site of action of this modulator on the presynaptic terminals. Several hypotheses could be put forth to explain this result. The increase in release probability by FSK could per se be responsible for the effects of AEA. However, when we raised the release probability by other means, such as 4-AP, AEA no longer facilitated glutamate release. Therefore, we propose that coapplication with the adenylate cyclase activator may be important to increase the potency of AEA at VR1 (De Petrocellis et al., 2001), because AEA is characterized by a fast metabolism (Di Marzo et al., 1998a) and has a weaker potency at VR1 than capsaicin (Ross et al., 2001).

A role for AEA on VR1 in the CNS has also been described in the hippocampus (Al-Hayani et al., 2001) where AEA per se was shown to enhance GABAergic transmission. The elevated expression of VR1 in the hippocampus compared with the midbrain (Szabo et al., 2002) could explain an effect of AEA in this brain area even without forskolin.

The hypothesis that glutamatergic signaling might be under the tonic control of VR1 in the midbrain is supported by the previous finding of extremely high levels of AEA in this region (Di
Marzo et al., 2000a). We now report that VR1 is significantly expressed and AEA is very abundant in slices identical to those used for the electrophysiological studies, thus strengthening the hypothesis of an endogenous AEA stimulation of VR1. The amount of AEA found in midbrain slices is likely to yield a local concentration of almost $0.4 \mu \mathrm{M}$, which has been shown to be sufficient to activate VR1 receptors (De Petrocellis et al., 2001). AEA could be released in the SNc by striatal and substantia nigra reticulata afferents and taken up by VR1-expressing glutamatergic terminals. However, we cannot rule out the possibility that other, more potent endovanilloids, such as the recently identified NADA (Huang et al., 2002), could also play a major role in the tonic activation of VR1, because the SNc contains high levels of the biosynthetic precursor of NADA, dopamine.

In conclusion, our results strengthen the hypothesis that VR1 could act in the brain as a receptor for eicosanoid derivatives, such as anandamide. The function of VR1 in the CNS appears to be primarily devoted to the modulation of synaptic transmission, enhancing excitatory neurotransmission in the locus ceruleus and in the substantia nigra (i.e., present study; Marinelli et al., 2002a) and inhibiting neurotransmission in the hippocampus (Al-Hayani et al., 2001). In the ventral midbrain, a tonic modulation of the glutamatergic synaptic inputs by VR1s is likely to play an important role in the regulation of the firing discharge of SNc dopaminergic neurons that is strictly dependent on the efficacy of excitatory inputs (Overton and Clark, 1997). Thus, endogenous stimulation of VR1 could be implicated in motivation and reward mechanisms linked to the dopaminergic system (Schultz, 1986; Mirenowicz and Schultz, 1996).

\section{References}

Acs G, Palkovits M, Blumberg PM (1994) Comparison of $\left[{ }^{3} \mathrm{H}\right]$ resiniferatoxin binding by the vanilloid (capsaicin) receptor in dorsal root ganglia, spinal cord, dorsal vagal complex, sciatic and vagal nerve and urinary bladder of the rat. Life Sci 55:1017-1026.

Al-Hayani A, Wease KN, Ross RA, Pertwee RG, Davies SN (2001) The endogenous cannabinoid anandamide activates vanilloid receptors in the rat hippocampal slice. Neuropharmacology 41:1000-1005.

Bisogno T, Maurelli S, Melck D, De Petrocellis L, Di Marzo V (1997) Biosynthesis, uptake, and degradation of anandamide and palmitoylethanolamide in leukocytes. J Biol Chem 272:3315-3323.

Bisogno T, Berrendero F, Ambrosino G, Cebeira M, Ramos JA, FernandezRuiz JJ, Di Marzo V (1999) Brain regional distribution of endocannabinoids: implications for their biosynthesis and biological function. Biochem Biophys Res Commun 256:377-380.

Caterina MJ, Schumacher MA, Tominaga M, Rosen TA, Levine JD, Julius D (1997) The capsaicin receptor: a heat-activated ion channel in the pain pathway. Nature 389:816-824.

Dawbarn D, Harmar AJ, Pycock CJ (1981) Intranigral injection of capsaicin enhances motor activity and depletes nigral 5-hydroxytryptamine but not substance P. Neuropharmacology 20:341-346.

De Petrocellis L, Harrison S, Bisogno T, Tognetto M, Brandi I, Smith GD, Creminon C, Davis JB, Geppetti P, Di Marzo V (2001) The vanilloid receptor (VR1)-mediated effects of anandamide are potently enhanced by the cAMP-dependent protein kinase. J Neurochem 77:1660-1663.

Di Marzo V, Melck D, Bisogno T, De Petrocellis L (1998a) Endocannabinoids: endogenous cannabinoid receptor ligands with neuromodulatory action. Trends Neurosci 21:521-528.

Di Marzo V, Bisogno T, Melck D, Ross R, Brockie H, Stevenson L, Pertwee R, De Petrocellis L (1998b) Interactions between synthetic vanilloids and the endogenous cannabinoid system. FEBS Lett 436:449-454.

Di Marzo V, Hill MP, Bisogno T, Crossman AR, Brotchie JM (2000a) Enhanced levels of endogenous cannabinoids in the globus pallidus are associated with a reduction in movement in an animal model of Parkinson's disease. FASEB J 14:1432-1438. 
Di Marzo V, Breivogel CS, Tao Q, Bridgen DT, Razdan RK, Zimmer AM, Zimmer A, Martin BR (2000b) Levels, metabolism, and pharmacological activity of anandamide in $\mathrm{CB}(1)$ cannabinoid receptor knockout mice: evidence for non- $\mathrm{CB}(1)$, non- $\mathrm{CB}(2)$ receptor-mediated actions of anandamide in mouse brain. J Neurochem 75:2434-2444.

Di Marzo V, Goparaju SK, Wang L, Liu J, Batkai S, Jarai Z, Fezza F, Miura GI, Palmiter RD, Sugiura T, Kunos G (2001a) Leptin-regulated endocannabinoids are involved in maintaining food intake. Nature 410:822-825.

Di Marzo V, Bisogno T, De Petrocellis L (2001b) Anandamide: some like it hot. Trends Pharmacol Sci 22:346-349.

Hajos M, Jancso G, Engberg G (1987) Capsaicin-induced excitation of locus coeruleus neurons. Acta Physiol Scand 129:415-420.

Hajos M, Engberg G, Nissbrandt H, Magnusson T, Carlsson A (1988) Capsaicin-sensitive vasodilatatory mechanisms in the rat substantia nigra and striatum. J Neural Transm 74:129-139.

Hori T, Shibata M, Kiyohara T, Nakashima T, Asami A (1988) Responses of anterior hypothalamic-preoptic thermosensitive neurons to locally applied capsaicin. Neuropharmacology 27:135-142.

Huang SM, Bisogno T, Trevisani M, Al-Hayani A, De Petrocellis L, Fezza F, Tognetto M, Petros TJ, Krey JF, Chu CJ, Miller JD, Davies SN, Geppetti P, Walker JM, Di Marzo V (2002) An endogenous capsaicin-like substance with high potency at recombinant and native vanilloid VR1 receptors. Proc Natl Acad Sci USA 99:8400-8405.

Jackson A, Crossman AR (1983) Nucleus tegmenti pedunculopontinus: efferent connections with special reference to the basal ganglia, studied in the rat by anterograde and retrograde transport of horseradish peroxidase. Neuroscience 10:725-765.

Julius D, Basbaum AI (2001) Molecular mechanisms of nociception. Nature 413:203-210.

Katz B, Miledi R (1969) Spontaneous and evoked activity of motor nerve endings in calcium Ringer. J Physiol (Lond) 203:689-706.

Kita H, Kitai ST (1987) Efferent projections of the subthalamic nucleus in the rat: light and electron microscopic analysis with the PHA-L method. J Comp Neurol 260:435-452.

Kress M, Zeilhofer HU (1999) Capsaicin, protons and heat: new excitement about nociceptors. Trends Pharmacol Sci 20:112-118.

Maccarrone M, Lorenzon T, Bari M, Melino G, Finazzi-Agro A (2000) Anandamide induces apoptosis in human cells via vanilloid receptors. Evidence for a protective role of cannabinoid receptors. J Biol Chem 275:31938-1945.

Marinelli S, Vaughan CW, Christie MJ, Connor M (2002a) Capsaicin activation of glutamatergic synaptic transmission in the rat locus coeruleus in vitro. J Physiol (Lond) 543:531-540.

Marinelli S, Berretta N, Bernardi G, Mercuri NB (2002b) Presynaptic effects of VR1 activation in the ventral midbrain. Soc Neurosci Abstr 28:550.10.

McDonald AJ (1996) Glutamate and aspartate immunoreactive neurons of the basolateral amygdala: colocalization of excitatory amino acids and projections to the limbic circuit. J Comp Neurol 365:367-379.

Melck D, Bisogno T, De Petrocellis L, Chuang H, Julius D, Bifulco M, Di Marzo V (1999) Unsaturated long-chain $\mathrm{N}$-acyl-vanillyl-amides (NAVAMs): vanilloid receptor ligands that inhibit anandamide-facilitated transport and bind to CB1 cannabinoid receptors. Biochem Biophys Res Commun 262:275-284.

Mercuri NB, Bonci A, Calabresi P, Bernardi G (1996) Characterization of a barium-sensitive outward current following glutamate application on rat midbrain dopaminergic cells. Eur J Neurosci 8:1780-1786.

Mezey E, Toth ZE, Cortright DN, Arzubi MK, Krause JE, Elde R, Guo A, Blumberg PM, Szallasi A (2000) Distribution of mRNA for vanilloid receptor subtype 1 (VR1), and VR1-like immunoreactivity, in the central nervous system of the rat and human. Proc Natl Acad Sci USA 97:3655-3660.

Mirenowicz J, Schultz W (1996) Preferential activation of midbrain dopamine neurons by appetitive rather than aversive stimuli. Nature 379:449-451.
Naito A, Kita H (1994) The cortico-nigra projection in the rat: an anterograde tracing study with biotinylated dextran amine. Brain Res 637:317-322.

Nakatsuka T, Furue H, Yoshimura M, Gu JG (2002) Activation of central terminal vanilloid receptor-1 receptors and $\alpha \beta$-methylene-ATP-sensitive $\mathrm{P} 2 \mathrm{X}$ receptors reveals a converged synaptic activity onto the deep dorsal horn neurons of the spinal cord. J Neurosci 22:1228-1237.

Overton PG, Clark D (1997) Burst firing in midbrain dopaminergic neurons. Brain Res Brain Res Rev 25:312-334.

Pertwee RG (1997) Pharmacology of cannabinoid CB1 and CB2 receptors. Pharmacol Ther 74:129-180.

Ross RA, Gibson TM, Brockie HC, Leslie M, Pashmi G, Craib SJ, Di Marzo V, Pertwee RG (2001) Structure-activity relationship for the endogenous cannabinoid, anandamide, and certain of its analogues at vanilloid receptors in transfected cells and vas deferens. Br J Pharmacol 132:631-640.

Sasamura T, Sasaki M, Tohda C, Kuraishi Y (1998) Existence of capsaicinsensitive glutamatergic terminals in rat hypothalamus. NeuroReport 9:2045-2048.

Schultz W (1986) Responses of midbrain dopamine neurons to behavioral trigger stimuli in the monkey. J Neuophysiol 56:1439-1461.

Schumacher MA, Moff I, Sudanagunta SP, Levine JD (2000) Molecular cloning of an $\mathrm{N}$-terminal splice variant of the capsaicin receptor. Loss of $\mathrm{N}$-terminal domain suggests functional divergence among capsaicin receptor subtypes. J Biol Chem 275:2756-2762.

Shin J, Cho H, Hwang SW, Jung J, Shin CY, Lee SY, Kim SH, Lee MG, Choi YH, Kim J, Haber NA, Reichling DB, Khasar S, Levine JD, Oh U (2002) Bradykinin-12-lipoxygenase-VR1 signaling pathway for inflammatory hyperalgesia. Proc Natl Acad Sci USA 99:10150-10155.

Smart D, Gunthorpe MJ, Jerman JC, Nasir S, Gray J, Muir AI, Chambers JK, Randall AD, Davis JB (2000) The endogenous lipid anandamide is a full agonist at the human vanilloid receptor (hVR1). Br J Pharmacol 129:227-230.

Smith GD, Gunthorpe MJ, Kelsell RE, Hayes PD, Reilly P, Facer P, Wright JE, Jerman JC, Walhin JP, Ooi L, Egerton J, Charles KJ, Smart D, Randall AD, Anand P, Davis JB (2002) TRPV3 is a temperature-sensitive vanilloid receptor-like protein. Nature 418:186-190.

Szabo T, Biro T, Gonzalez AF, Palkovits M, Blumberg PM (2002) Pharmacological characterization of vanilloid receptor located in the brain. Brain Res Mol Brain Res 98:51-57.

Szallasi A, Di Marzo V (2000) New perspectives on enigmatic vanilloid receptors. Trends Neurosci 23:491-497.

Tominaga M, Caterina MJ, Malmberg AB, Rosen TA, Gilbert H, Skinner K, Raumann BE, Basbaum AI, Julius D (1998) The cloned capsaicin receptor integrates multiple pain-producing stimuli. Neuron 21:531-543.

Urban L, Dray A (1992) Synaptic activation of dorsal horn neurons by selective $\mathrm{C}$-fibre excitation with capsaicin in the mouse spinal cord in vitro. Neuroscience 47:693-702.

Wahl P, Foged C, Tullin S, Thomsen C (2001) Iodo-resiniferatoxin, a new potent vanilloid receptor antagonist. Mol Pharmacol 59:9-15.

White R, Hiley CR (1998) The actions of some cannabinoid receptor ligands in the rat isolated mesenteric artery. Br J Pharmacol 125:533-541.

Xu H, Ramsey IS, Kotecha SA, Moran MM, Chong JA, Lawson D, Ge P, Lilly J, Silos-Santiago I, Xie Y, DiStefano PS, Curtis R, Clapham DE (2002) TRPV3 is a calcium-permeable temperature-sensitive cation channel. Nature 418:181-186.

Yang K, Kumamoto E, Furue H, Yoshimura M (1998) Capsaicin facilitates excitatory but not inhibitory synaptic transmission in substantia gelatinosa of the rat spinal cord. Neurosci Lett 255:135-138.

Zygmunt PM, Petersson J, Andersson DA, Chuang H, Sorgard M, Di Marzo V, Julius D, Hogestatt ED (1999) Vanilloid receptors on sensory nerves mediate the vasodilator action of anandamide. Nature 400:452-457. 